\title{
A relevância ética da contemplação estética
}

\author{
Margit Ruffing \\ Johannes Gutenberg-Universität - Mainz (Alemanha)
}

\begin{abstract}
Schopenhauer organized his philosophy of the world as will and representationsystematically, dividing the work into four sections. The unity of the essence of the worldarises in different ways, according to the four books of the main work, by means of ournatural volitional and purposive cognition (book 1), the recognition of the "objectity" of thewill, experienced on the own body (book 2), the possibility of ideal cognition, freed fromthe will, in aesthetic contemplation (book 3) up to the understanding ("Durchschauung") of the principium individuationis: the self-knowledge of the will (book 4). In this article, the theory of aesthetic contemplation is regarded as a philosophy of consciousness, whichlegitimizes the central importance of the third Book for Schopenhauer's philosophical systemas a whole. Our central reflections refer to the specific mental attitude of "Besonnenheit"insofar as it is both a condition of knowledge and a characteristic of human morality. Hencethe human capacity for morality is present in actual aesthetic contemplation - as a conditionof the possibility of acting morally.
\end{abstract}

\section{Considerações introdutórias ao sistema do Mundo como vontade e representação}

A filosofia de Schopenhauer, que considera e explica esse mundo como vontade e representação, quer tornar compreensível esse pensamento - de que o mundo é autoconhecimento da vontade ${ }^{1}$. Assim, ela forma um sistema, e ela precisa fazer isso, pois a verdadeira filosofia corresponde, segundo o próprio ponto de vista de Schopenhauer, a um todo orgânico, a saber, à vida mesma e a seu significado, que foi concebido, expresso em conceitos e colocado em uma forma sistemática - por ele, o filósofo. E esta serve para informar a compreensão filosófica da essência do mundo, torná-la acessível ao conhecimento de outros ${ }^{2}$. O sistema não é para Schopenhauer, portanto, a coisa mesma, mas a forma de representação, considerada por ele ideal, do pensamento do mundo como autoconhecimento, como "autoapresentação" da vontade. Dela surge a estrutura dualista do sistema schopenhaueriano ${ }^{3}$, a partição em dois livros respectivos, que

\footnotetext{
${ }^{1}$ Siehedazuauch: Rudolf Malter: Der eineGedanke. HinführungzurPhilosophie Arthur Schopenhauers.Darmstadt: WissenschaftlicheBuchgesellschaft. 2. Aufl. $2010{ }^{\left[{ }^{1} 1988\right] .}$

${ }^{2}$ Dazuäußertsich Schopenhauer anverschiedenenStellen seines Werkes, s. besonders die Vorredezur 2. Auflage der Welt alsWille und Vorstellung, und W I, § 15, dort 98-99.

${ }^{3}$ Das Verhältnis von dualistischer Form und inhaltlicherEinheithabeichanandererStellebehandelt, s. „Die Duplizitätsstruktur des Bewußtseinsbei Schopenhauer und C. G. Jung, oder: 1+1=1“. In: 86. Schopenhauer-Jahrbuch (Würzburg) 2005, 195-212.
} 
tratam da representação, do conhecimento, e do objeto representado, conhecido, ora estando sob o princípio de razão suficiente, ora devendo ser analisados independentemente do mesmo. Examinando bem, no mundo como vontade e representação de Schopenhauer estamos sempre lidando com uma teoria do conhecimento. No primeiro livro, trata-se do conhecimento "cotidiano" e do científico, que ordena tudo em relações de causa e efeito; o segundo livro explica um conhecimento toto genere diferente, a saber, a certeza sentida de que o próprio ser não se sujeita a uma causalidade teleológica da natureza, ou seja, a compreensão da volitividade essencial (das wesentlich Willenshafte) de nossa natureza, e explica que essa pode ser transposta (por analogia) ao mundo inteiro; o terceiro livro fala novamente de uma "forma de conhecimento" bem diferente, da contemplação estética, e o quarto livro tem como tema, por fim, o completo autoconhecimento da vontade, que tem consequências práticas, possibilitando ao ser humano uma atitude moral voltada contra a vontade por natureza egoísta e um comportamento moral e altruísta.

Dito com outras palavras: os quatro livros, nos quais Schopenhauer desenvolve sistematicamente sua filosofia, têm como base apenas duas questões de conhecimento - a questão a respeito de o que do conhecimento, da essência, do significado do mundo, e a questão a respeito do acesso ao conhecimento do essencial, a respeito do como do conhecimento. Como se sabe, o segundo livro responde à primeira questão com a metafísica da vontade, cujo aspecto prático é apresentado no quarto livro como ética da compaixão. Mas só o que possibilita a resposta à questão sobre a essência, o momento sistematicamente decisivo e que liga todos os quatro livros, é de fato a questão sobre o como, ou falando de forma kantiana, a questão sobre as condições da possibilidade do conhecimento. Embora as explicações teórico-cognitivas de Schopenhauer encontrem-se, como é amplamente sabido, principalmente no primeiro livro, essa questão só vai ser realmente respondida no meu ponto de vista a partir do terceiro livro, também a respeito de seu "ponto de transição" entre o conhecimento primeiro da vontade, imperfeito, e a plena compreensão do principium individuationis, entre metafísica e ética, dito provocativamente: entre razão teórica e prática. A teoria de Schopenhauer da contemplação estética é uma filosofia das artes e da consciência, 
ao mesmo tempo em que a última legitima o significado central do terceiro livro para o sistema como um todo. ${ }^{4}$

Como mostra a história de sua recepção, o terceiro livro do Mundo como vontade e representação foi de fato frequentemente desassociado de seu contexto sistemático, e foi recebido com sucesso de público como teoria da arte, doutrina das ideias e doutrina do gênio. ${ }^{5}$ Mas ele assume uma posição especial, segundo minha compreensão, não por causa desses aspectos, mas sim porque ele trata de uma atitude mental especial, que tanto é parte da arte como forma de conhecimento como é parte também da consciência moral: refiro-me com isso ao que Schopenhauer chama de "clareza de consciência" (Besonnenheit): Clareza de consciência quer dizer condição de conhecimento $e$ indicativo da moralidade humana. $^{6}$

A questão sobre a constituição do conhecimento da essência e da nossa capacidade de conhecimento que ela suscita encontra-se assim em estreita correlação com a questão da faculdade de moralidade do ser humano. Isso é o que eu gostaria de tentar mostrar nesta conferência. Por isso, irei primeiramente expor rapidamente a contemplação estética, como ela é apresentada por Schopenhauer no terceiro livro do Mundo como vontade e representação, e então tratarei da clareza de consciência a ela correspondente como característica intelectual da moralidade humana para definir mais de perto a relevância ética da contemplação estética.

\section{A contemplação estética}

A doutrina das ideias como tal já é parte integrante do segundo livro; ela descreve a convicção de Schopenhauer do fato de que a vontade entra na representação como princípio metafísico e essa “objetivação" se realiza de acordo com uma determinada hierarquia ou gradação, em que cada nível caracteriza a forma original, o protótipo, ou seja, a ideia das objetivações particulares correspondentes. As ideias referem-se a uma transcendência do conhecimento

\footnotetext{
${ }^{4}$ DieseThematikstehtimZentrummeiner Dissertation: „,WillezurErkenntnis“. Die Selbsterkenntnis des Willens und die Idee des Menschen in der ästhetischenTheorie Arthur Schopenhauers, veröffentlichtim Online-Archiv der UniversitätsbibliothekMainzhttp://archimed.uni-mainz.de/pub/2002/0060/diss.pdf.

${ }^{5}$ Vgl. die BibliographiezurÄsthetikSchopenhauers, in: ,WillezurErkenntnis“, s. Anm. 4, 179-200.

${ }^{6}$ Eine umfassende Analyse des Bedeutungsspektrums von Besonnenheit bei Schopenhauer findet sich in einem Aufsatz von Matthias Koßler: „Zur Rolle der Besonnenheit in der Ästhetik Arthur Schopenhauers“. In: 83. Schopenhauer-Jahrbuch (Würzburg) 2002, 119-133.
} 
segundo o princípio de razão suficiente, a uma nova forma de conhecimento. Para destacar o caráter especial da ideia, Schopenhauer a compara ao conceito:

[...] o conceito assemelha-se a um recipiente morto, no qual o que foi colocado permanece lado a lado, mas do qual não se pode retirar (através de juízos analíticos) nada além do que foi colocado (através da reflexão sintética): a ideia, por outro lado, desenvolve representações naquele que a concebeu, que são novas em relação ao conceito homônimo à ideia: ela assemelha-se a um organismo vivo, que se desenvolve, dotado de força gerativa, que produz aquilo que não se encontra dentro dele. (W I, 227)

Aqui o conceito é caracterizado metaforicamente como um "recipiente morto", contraposto à ideia, para evocar de forma especial o aspecto vivo, dinâmico, criativo, inerente a ela: à ideia é atribuído um momento inovativo, em comparação ao resultado da atividade da razão, ou seja, ao conceito. De um lado, trata-se de fixar o conhecimento e torná-lo comunicável: no fim desses esforços tem-se o conceito. De outro lado, o que o conceito caracteriza só é conhecido como o que é quando o indivíduo cognoscente concebe sua ideia. Nessa forma de conhecimento, a ideia encontra-se no início: ela ativa processos da consciência no sentido mais amplo, originando representações "que são novas em relação ao conceito homônimo à ideia." A comparação da ideia com um organismo vivo, que se desenvolve, dotado de "força gerativa" sugere, no meu ponto de vista, que ela não deva ser concebida como forma ou "recipiente" do conhecimento, e também não como um conteúdo qualquer, mas sim como força, que move e modifica algo na consciência, para gerar um conhecimento da coisa, que vai além do simples conceito. Assim, eu proponho pensar essa representação, caracterizada por Schopenhauer como não-causal, como força ou habilidade da consciência não afetadas por determinações espaciais e temporais.

O mundo como vontade e representação pode ser interpretado por meio de uma concepção da ideia concebida como força da seguinte maneira: o mundo é de acordo com a coisa "mundo da vontade como representação". Para nós o mundo é, na medida em que nós, partindo necessariamente da fenomenalidade, o conhecemos segundo sua essência, "mundo da representação como vontade" - a ideia de sua parte garante o olhar no essencial na e dentro da representatividade, ela significa a mais elevada intensidade da vontade na mais pura 
representatividade. Assim vista, ela atesta uma atividade transcendental da consciência; somente a ideia é uma garantia para o entendimento de declarações filosóficas sobre o "Mundo como vontade $e$ representação". O conhecimento da vontade como essência do mundo torna-se assim na ideia uma autocompreensão viva, na qual volitivo (Wollendes) e cognoscente (Erkennendes) passam a ser experimentados como um todo inseparável.

Essa experiência, de acordo com sua realidade e possibilidade, é a contemplação estética: como evento, como constituição da consciência. A contemplação estética é uma forma de conhecimento, que não parece depender do conceito, ou não para nele, mas transcende o relacional e o formal. Pode ser falado em duplo sentido do caráter transitório do conhecimento estético: 1) A experiência da visão das ideias é per se fugaz e mesmo sempre em transição; 2) a posição da teoria das ideias no terceiro livro do Mundo como vontade e representação pode valer nesse sentido como preparação para a ética, que supera essa fugacidade no sentido de uma atividade duradoura da consciência.

Essa concepção da contemplação estética como atividade da consciência é apropriada ao conhecimento e entendimento do essencial, porque ela compreende a limitação ao particular, ao individual, como não essencial, que não faz parte do essencial da vida; ou seja, no lado do objeto que é considerado e leva à contemplação, como também no lado do sujeito que supera na contemplação a própria limitação - dolorosa - ao individual. O "autoesquecimento" do qual Schopenhauer fala ${ }^{7}$ não é outra coisa que um esquecimento da autocompreensão cotidiana, em cujo centro um "eu" se encontra, a partir do qual tudo o mais é conhecido e avaliado. Esse "eu" encontra-se no ponto central de todas as relações, ele é ligado a elas e condicionado por elas - o que por si só já é sentido como limitação e impedimento da própria vontade. Essa sensação é reforçada através do conhecimento do intelecto, pelo fato de que a condicionalidade causal determina o mundo inteiro e por assim dizer o mantém preso, mas também através da Experiência, pelo fato de que as vontades particulares concorrentes não podem se satisfazer e se direcionam umas contra as outras dolorosamente.

Em relação a isso, Schopenhauer descreve a contemplação estética como possibilidade de escapar dessa situação por pouco tempo, tanto em relação ao

\footnotetext{
${ }^{7}$ Vgl. W I, 218 ff., auch § 39, „Über das Erhabene“, hier S. 238.
} 
conhecimento intelectual, quanto ao que concerne à experiência do sofrimento. Schopenhauer julga a forma de conhecimento estético como essencial, porque ela aperfeiçoa na contemplação estética a consciência corporal e intuitiva imediata a um ser-consciente da beleza, livre de interesse e finalidade. Além disso, a compreensão que reside aí da consubstancialidade do sujeito e objeto é integrada na reflexão filosófica subsequente: o segundo livro, relativo aos objetos, isso resulta no conceito da objetidade adequada, ou seja, na teoria das ideias, no quarto livro a compreensão da consubstancialidade de todos os fenômenos da vontade tornam-se a compreensão fundamental do ser racional homem, capaz de moralidade. Para que a contemplação estética se apresente, é preciso da beleza do objeto, que implica algo a mais que si mesmo, mas também da clareza de consciência do sujeito. Na sequência será falado sobre isso.

\section{Clareza de consciência}

Primeiramente, precisamos nos voltar mais uma vez para o conceito de “objetidade”, de tão difícil tradução, que o próprio Schopenhauer iguala à ideia e à visibilidade do ser que passa a fenômeno, caracterizando a ideia como objetidade da vontade e com isso do ser, objetivação no mais alto nível. Unicamente a ideia tem a característica de ser uma objetivação ideal da vontade de tal forma apropriada, que a fenomenalidade não desvia do essencial, mas antes leva a ele, que a fenomenalidade torna-se compreensível e o essencial visível - e pode ser conhecido:

Que a correta e clara concepção do mundo é a fonte da sabedoria, não o saber abstrato, isso pode ser compreendido a priori do fato de que o conhecimento das ideias (veja o terceiro livro) é um conhecimento claro, seu conhecimento dá a mais elevada sabedoria, não a observação das mudanças infinitas no tempo, nem da multiplicidade incontável no espaço, porque tudo isso é apenas fenômeno das ideias e apenas digno de consideração enquanto não se conheça as ideias. (HN III, 100/ Foliant I, Nr. 57: Berliner MS, 1821)

Além da ideia em geral, o conceito de objetidade caracteriza também a existência-visível da vontade no indivíduo corpóreo, por exemplo, com a frase "meu corpo é a objetidade da minha vontade"; isso significa também "o 
conhecimento que eu tenho da minha vontade [...], não pode ser separado do conhecimento da minha vontade" (W I 121). Com isso se chega a uma declaração que postula a identidade do meu próprio corpo, do meu respectivo corpo e vontade. A consciência original do ser, a compreensão elementar sentida, de que eu sou vontade é ao mesmo tempo uma restrita ao sujeito individual e uma geral, que vale para cada sujeito individual. No que eu me conheço corporal e conscientemente como minha vontade, eu sei da ideia do meu ser individual como unidade de corpo e consciência-eu e vivencio, falando de forma moderna, uma autoconsciência "holística". Esse saber sobre a ideia do indivíduo tem ao fim o mesmo conteúdo que o saber adquirido através da contemplação estética: é a certitude do ser onipresente e universal, de fato uma certitude sentida.

Da ação conjunta de todas as capacidades de conhecimento e de objeto ideal resulta a especial constituição da clareza de consciência (Bewusstseinverfassung der Besonnenheit). Eu sou da opinião que ela deve ser pensada menos como qualidade que como Postura, no sentido de uma consciência atenciosa, refletida, integrativa, da qual conhecimentos filosóficos, como também comportamento (moral) se originam. Precisamente na postura da consciência clara (besonnene Haltung) expressa-se a ideia que constitui segundo a teoria das ideias de Schopenhauer o mais elevado nível da objetivação da vontade: a do ser humano cognoscitivo e racional, para quem vale:

Agora que, nas gradações infinitas, eleva-se a lucidez da consciência, a sua clareza torna-se mais e mais presente [...]. (W II, 437)

Schopenhauer já fala em sua dissertação da clareza de consciência com esse significado geral:

[...] Clareza de consciência [...], a faculdade de tomar consciência, vir a si mesmo, é na verdade a raiz de todas as suas atividades teóricas e práticas, pela qual o ser humano supera tanto o animal. [...] $(\mathrm{G}, 117$ / Diss.)

Clareza de consciência leva assim à "tomada de consciência", que pode ser entendida também como reflexão; o ser humano sensato é capaz de encontrar em si 
o sentido do mundo, bem como o de si mesmo a partir da clara consciência da pura intuição, "tornar-se consciente de algo". Trata-se assim na clareza de consciência de uma aplicação adequada da razão humana mesma.

Para realizar essa requerida e extraordinária atividade de abstração, que transcende a representação da compreensão no princípio metafísico, é preciso segundo Schopenhauer não somente de uma "compreensão elementar" 8 sentida, mas de uma postura interior especial, que metaforicamente falando parece se igualar a um salto interior: é preciso da clareza de consciência, para a qual auxilia apenas o distanciamento de sentir e querer através da reflexão da "compreensão elementar" no conhecimento. A ideia do indivíduo compreende em si a convicção de que o homem possui a capacidade de identificar com a sua função de conhecimento, ou seja, de ser sujeito puramente cognoscitivo, para quem a simples vontade de vida se apresenta como o que se autoconhece, como a vontade de autoconhecimento. Schopenhauer imagina concretamente essa condição da clareza de consciência como resultado de uma vida ascética, cuja finalidade é satisfazer apenas as necessidades físicas de sobrevivência, para suprimir amplamente as sensações de prazer-desprazer do corpo, que são a vontade mesma, como ela ocorre na consciência - em uma palavra: como resultado da negação da vontade. ${ }^{9}$

Por isso Schopenhauer descreve consequentemente no quarto livro que e porque a clareza de consciência pode ser alcançada duradoura e permanentemente através da negação da vontade na ascese. A redução máxima dos atos da vontade que ocupam a consciência, os quais produzem - para complementar o entendimento - um sujeito da vontade ao custo de um do conhecimento, deve assim otimizar a capacidade cognitiva humana. A negação da vontade corresponde a uma recusa a aceitar o poder das manifestações premenciais vitais não associadas ao conhecimento como prioritárias a todas as outras experiências. Só sob essa pressuposição é possível conhecimento (-racional) sistemático e filosófico:

\footnotetext{
${ }^{8}$ Der Begriff „Elementareinsicht“ geht auf Rudolf Malters fundamentaler Schopenhauer-Exegese zurück, auf die hier ausdrücklich verwiesen sei: Arthur Schopenhauer - Transzendentalphilosophie und Metaphysik des Willens. Stuttgart-Bad Cannstatt: frommann-holzboog, 1991, hier insbesondere der Abschnitt „Die Schwierigkeit der Verallgemeinerbarkeit der metaphysischen Elementareinsicht“, 223247.

${ }^{9}$ S. hierzu die Definition von Askese, W I, 449: „Jener aber, der, das principium individuationis durchschauend, das Wesen der Dinge an sich und dadurch das Ganze erkennt, [...] sieht sich an allen Stellen zugleich [...]. - Sein Wille wendet sich, bejaht nicht mehr sein eigenes, sich in der Erscheinung spiegelndes Wesen, sondern verneint es. Das Phaenomen, wodurch dieses sichkundgiebt, ist der Uebergang von der TugendzurAskesis."Vgl. auch Ruffing, ,,WillezurErkenntnis“, Kap.4, besonders $128-140$.
} 
Pois justo o que os místicos cristãos chamam de graça eficaz e reencarnação é para nós a única manifestação imediata da liberdade da vontade [...] A possibilidade da liberdade que assim se manifesta é o maior privilégio do ser humano, que faltará eternamente ao animal, pois a clareza de consciência da razão, que, independentemente da impressão do presente, faz perder de vista o todo da vida, é a condição da mesma. (W I, 478; itálico meu)

Mas Schopenhauer não descreve a clareza de consciência apenas como uma postura, que é reservada aos ascetas e aos santos, mas que ocorre sempre onde aconteça o conhecimento de ideias, que nos aproximam da verdade e sabedoria; ela corresponde a uma "forma de conhecimento", que vai além da certitude, ou seja, da arte e demanda "genialidade" ou clareza de consciência:

O gênio tem [...] o grau muito elevado e a vantagem de uma duração mais demorada dessa forma de conhecimento, que o faz manter na mesma a clareza de consciência que é exigida para repetir o que é assim conhecido em uma obra arbitrária, repetição que é a obra de arte. (W I, 229; grifo meu)

Ao explicar como a verdade objetiva e a veracidade subjetiva convergem na contemplação estética, Schopenhauer desenvolve um autoentendimento e um entendimento do mundo filosófico, que tem sua "autenticação em si" (W II, 533). Sua teoria da contemplação estética torna compreensível o mundo como um autoconhecimento que se materializa e se realiza do vivo mesmo, ou do eu vivo. Sob o aspecto da teoria do conhecimento, ele é pressuposto para a "sabedoria", com o que Schopenhauer se refere à explicação filosófica do autoentendimento verdadeiro do ser humano, que se baseia na clareza de consciência. Em perspectiva prática, como expressão da negação da própria vontade - e por fim até da vontade em geral - ele é pressuposto para uma atitude somente a partir da qual a ação moral é possível, que Schopenhauer chama de "bens da disposição moral". Colocar-se no lugar do outro e de certa forma também agir no seu lugar, para seu bem, para ele. Assim, o terceiro livro não é só a "soma", a síntese, do primeiro e do segundo, mas também pressuposto necessário para o quarto livro, no qual Schopenhauer completa a sua filosofia. 